\title{
Confusões e desrespeito: uma (re)interpretação possível das falas dos moradores de favelas
}

Confusions and disrespect: A possible (re)interpretation of speeches from favela dwellers

\section{Marcus Cardoso}

\section{(2) OpenEdition}

Edição electrónica

URL: http://journals.openedition.org/aa/1210

DOI: 10.4000/aa. 1210

ISSN: 2357-738X

\section{Editora}

Programa de Pós-Graduação em Antropologia Social (UnB)

\section{Edição impressa}

Data de publição: 1 dezembro 2014

Paginação: 261-282

ISSN: 0102-4302

\section{Refêrencia eletrónica}

Marcus Cardoso, «Confusões e desrespeito: uma (re)interpretação possível das falas dos moradores de favelas», Anuário Antropológico [Online], v.39 n.2 | 2014, posto online no dia 01 agosto 2017, consultado o 28 abril 2021. URL: http://journals.openedition.org/aa/1210 ; DOI: https://doi.org/ 10.4000/aa. 1210

\section{(c) $(1)(9)$}

Anuário Antropológico is licensed under a Creative Commons Atribuição-Uso Não-Comercial-Proibição de realização de Obras Derivadas 4.0 International. 


\title{
Confusões e desrespeito: uma (re)interpretação possível das falas dos moradores de favelas
}

\author{
Marcus Cardoso \\ CNPq/INCT-InEAC
}

Este artigo é dedicado a memória de Clara Mafra.

Em 2008, Machado da Silva \& Leite publicaram um artigo intitulado "Violência, crime e polícia: o que os favelados dizem quando falam desses temas?". Nele, são apresentadas 57 narrativas de moradores de favelas cariocas sobre seu cotidiano, seus medos e a violência cometida por agentes da polícia e dos grupos que controlam a comercialização de drogas ilegais em suas localidades. Ao analisarem o rico e vasto material, os autores concluem que a questão de fundo a informar cada depoimento dos moradores é a insatisfação com as implicações da presença de policiais e traficantes dentro das favelas. ${ }^{1}$ Por implicações, entenda-se a interrupção da "estabilidade das rotinas diárias" provocadas pelas "explosões de violência” (Machado da Silva \& Leite, 2008:47) que os comportamentos adotados por traficantes e policiais desencadeiam. Em última análise, as explosões de violência são um problema porque prejudicam o cotidiano dessas localidades, atrapalhando ou impedindo que vigore um modelo ideal de sociabilidade.

Essa conclusão vai ao encontro das reflexões de Machado da Silva (2008) sobre como as representações da "violência urbana" têm modificado a forma como as relações sociais se constituem e se mantêm no Rio de Janeiro, mais especificamente nas favelas cariocas. Segundo ele, encontrar-nos-íamos diante de um cenário de "sociabilidade violenta" cuja maior característica seria o uso da força como princípio regulador das interações sociais, marcadas pela desconfiança, pelo medo e pela submissão que a ameaça à integridade física provoca. Essa situação faz com que as pessoas desenvolvam um "esforço adicional destinado a garantir a continuidade das rotinas, permanentemente ameaçadas" (Machado da Silva \& Leite, 2008:45). Isso gera desconforto, sobretudo para aquelas pessoas que residem em áreas onde as consequências da sociabilidade violenta são uma experiência tão próxima, como é o caso dos moradores de favelas. Por isso as queixas contra a polícia seriam uma reação "aos desajustamentos que suas práticas introduzem no fluxo das interações rotineiras nos territórios favelados”, de modo que "as críticas à violência policial podem ser resumidas da seguinte 
maneira: eles denunciam a violência, mas referem-se a outro problema: a quebra da rotina" (Machado da Silva \& Leite, 2008:73).

Tomando a liberdade de esquematizar os argumentos, pode-se dizer que, para os autores: 1) os queixosos apontam a quebra da rotina como um problema; 2) a problematização resulta da percepção de um aumento das situações de risco que ameaçam a vida e desorganizam o cotidiano dos moradores das favelas; 3 ) logo, a insatisfação dos moradores tem como alvo a desestabilização da "normalidade" da vida cotidiana. Presume-se uma relação automática ou direta, do tipo causa/efeito, entre os eventos que desestabilizam as rotinas das favelas e a insatisfação declarada, uma associação que Machado da Silva e Leite (2008) se esforçam em demonstrar no artigo.

Diferente de Machado da Silva \& Leite, que se concentram em demonstrar quais práticas são apontadas pelos moradores como problemáticas, estou interessado em explorar a dimensão simbólica dessas reclamações. Proponho retomar as narrativas presentes no artigo escrito pelos dois a partir de outra perspectiva, que, por desdobramento, conduzirá a uma interpretação que explora seus conteúdos. Para tal, é necessário adotar uma postura diferente diante das narrativas, aprofundando a reflexão sobre os sentidos que os moradores de favelas atribuem a determinados comportamentos considerados violentos e aos transtornos que eles provocam ao cotidiano local. Isso porque a resposta à pergunta formulada por Machado da Silva \& Leite, “o que os moradores dizem quando falam da vida nas favelas?”, não pode ser devidamente elaborada apenas pelo questionamento de quais são as práticas conduzidas por policiais e traficantes que transtornam o cotidiano dos moradores dessas áreas. É necessário perguntar também: que significado essas práticas adquirem para os moradores? Em quais contextos as queixas contra policiais e traficantes estão inseridas?

Neste artigo, sustento que as falas tão zelosamente recolhidas, organizadas e expostas por Machado da Silva \& Leite permitem ir além na reflexão sobre como certas categorias recorrentemente empregadas pelos moradores de favelas dão acesso à teia de significados que revelam visões de mundo centrais para compreender o que está em jogo quando eles falam das suas experiências. Tomar as categorias locais e os contextos nos quais elas surgem nas narrativas como objeto de análise permite-nos vislumbrar que as diversas modalidades de violência, os abusos, as humilhações, a interrupção abrupta do cotidiano e as transformações no modelo de socialidade não aparecem nas narrativas dessas pessoas como um problema em si. ${ }^{2}$

Dessa perspectiva é possível perceber que, na esfera simbólica, a desestabilização da vida ordinária por episódios como incursões policiais ou disputa entre Anuário Antropológico/2013, Brasília, UnB, 2014, v. 39, n. 2: 261-282 
grupos criminosos pelo controle de ponto de venda de drogas ilícitas, que via de regra desencadeiam tiroteios, são eventos que compõem um quadro mais amplo de práticas significadas como gestos de desconsideração da condição moral dos moradores não envolvidos com as atividades criminosas. Isso fica claro quando se percebe a recorrência com que categorias locais como "respeito", "pessoa de bem" e "trabalhador" surgem nas narrativas e pautam o entendimento que essas pessoas dão às práticas a que são submetidos ou que presenciam.

Por óbvio, a discussão que proponho detém-se principalmente nos depoimentos trazidos a público pelos dois autores. Mas não apenas. Com o intuito de enriquecer a análise e corroborar meus argumentos, lanço mão de dados etnográficos de meu trabalho de campo, realizado em duas favelas da cidade do Rio de Janeiro. ${ }^{3}$ A intenção é fazer com que essas duas pesquisas dialoguem, criando uma ponte que favoreça reflexões acerca das questões tratadas neste artigo.

\section{Sobre o que incomoda os moradores}

Comecemos pelo tráfico. Quando se trata de falar do comportamento dos indivíduos que pertencem às fileiras do grupo criminoso organizado a partir da venda de drogas ilícitas nas favelas, é comum escutar referências sobre um passado em que existia a figura do "bom bandido". A construção sobre o passado conta quase sempre com elementos como o "chefe" que era respeitoso com os demais moradores e que não permitia que seus subordinados roubassem dentro das favelas, nem que se fizesse uso explícito de drogas, ou que se agredissem ou humilhassem pessoas que não estavam envolvidas com práticas criminosas (Zaluar, 1985; Alvito, 2001; Machado da Silva, 2008). A construção de um discurso que traz elementos que remetem a outro tempo, contrapondo passado e presente, acaba por tornar os relatos sobre o comportamento do "movimento" hodiernamente ainda mais dramáticos. ${ }^{4}$ No caso estudado por mim, algumas pessoas de idade mais avançada recorriam a expressões como "o tempo da comunidade" para falar sobre uma época em que havia solidariedade entre os vizinhos, respeito aos mais velhos e amizade. Era uma época em que até os "marginais" respeitavam o lugar onde moravam e as pessoas que por lá viviam. Era o oposto do que acontecia à época da pesquisa, quando vigorava a desagregação, o desrespeito generalizado aos mais velhos e os abusos indiscriminados cometidos por membros da quadrilha local (Cardoso, 2010). As falas selecionadas por Machado da Silva \& Leite apresentam recursos narrativos muito semelhantes:

Não querem saber se tem criança no meio da rua, não querem saber se tem um morador na rua, eles querem o quê? [...] Hoje em dia o traficante senta na 
porta da pessoa, se droga na frente da pessoa sem ter aquele respeito. No meu tempo era proibido (Machado da Silva \& Leite, 2008:57, grifo meu).

Era proibido um menor ficar na boca-de-fumo, era proibido um traficante passar com a arma perto do morador (Machado da Silva \& Leite, 2008:57).

Eles [os traficantes] agora, eles não têm respeito pela comunidade, entendeu? Lá na [nome da favela], não têm. Porque sete horas da manhã [em frente a uma escola pública], as crianças formando para entrar [...], eles simplesmente, porque acharam que um ia invadir o território do outro, trocaram tiros ali (Machado da Silva \& Leite, 2008:66, grifo meu).

A juventude e a falta de enraizamento nas favelas é uma das explicações para o comportamento dos traficantes:

Eles estão ficando mais ousados, com requintes de crueldade por eles serem mais jovens [...], vão respeitar o morador com quem não têm ligação nenhuma, não cresceram? Não respeitam mesmo! (Machado da Silva \& Leite, 2008:58, grifo meu).

Se o que caracteriza o movimento hoje em dia é o "desrespeito" ao morador não envolvido com o crime organizado, no passado o que se via era justamente o contrário:

As pessoas sabiam que [eles] eram traficantes, eles também sabiam o papel deles, respeitavam o lugar em que moravam [...]. Agora não têm medo de nada, são muito mais abusados (Machado da Silva \& Leite, 2008:58, grifo meu).

Como se vê, "respeito" e "desrespeito" perpassam por todas as narrativas acima. Nesse conjunto, o último depoimento é especialmente interessante, pois permite trazer à tona outro elemento central para compreender do que esses moradores estão se queixando. Dizer que os traficantes sabiam seu papel e por isso respeitavam as pessoas é, ao mesmo tempo, colocar-se como moralmente superior a eles. Dentro desse entendimento, o que se está afirmando é que a motivação para o comportamento respeitoso por parte dos traficantes ou delinquentes no passado era o (suposto) reconhecimento, por partes destes últimos, de que suas escolhas eram moralmente inferiores às dos demais moradores; por isso, eles adotavam procedimentos que minimizavam o impacto da sua presença no local. Se, de fato, os traficantes agiam da forma como os moradores de favelas procuram nos convencer, pouco importa. Como me ensinou Ellen Woortmann (1994), a construção da memória social é sempre seletiva, parcial e informada 
pelos valores, contextos e interesses do presente. Dessa maneira, o significativo a ser observado aqui é que a referência ao passado define os parâmetros pelos quais o tráfico é visto por essas pessoas hoje em dia.

Que o comportamento dos traficantes era identificado como desrespeitoso para com os moradores não envolvidos com o bando, já está claro. Mas estamos diante de uma associação pura e simples entre atos perpetrados por traficantes e desrespeito? Acredito que não. Durante minha pesquisa nas favelas do Pavão-Pavãozinho e Cantagalo, não foi raro escutar, sobretudo de jovens, declarações que indicavam pouca preocupação com assassinatos de traficantes. Frases do tipo "enquanto eles estiverem se matando não tem problema" foram mais comuns do que eu poderia imaginar. E essa lógica era estendida aos consumidores de drogas que frequentavam as bocas de fumo, indivíduos dos mais desprezados dentro das favelas. Declarações dessa natureza permitiram-me inferir que o central nas queixas contra os traficantes era que suas práticas, em algumas ocasiões, vitimavam ou humilhavam as "pessoas de bem" (Cardoso, 2013, 2014). Tanto no meu exemplo etnográfico quanto no material publicado por Machado da Silva \& Leite, a problematização gira em torno do "tipo de pessoa" que experimentou a agressão, e não do ato em si. Ou seja, os procedimentos adotados são considerados desrespeitosos quando vitimam aqueles que não aderiram ao crime e que, por isso, estão em posição moralmente superior.

Analisarei agora algumas falas sobre os policiais. Como destacaram Machado da Silva \& Leite, a polícia era vista como igual ou pior do que os traficantes, já que agia com o mesmo desrespeito, embora coubesse a ela proteger e garantir a segurança da população. Por isso, as críticas contra seus agentes ganhavam contornos mais duros. A partir da leitura dos depoimentos percebe-se que, para os moradores entrevistados pelos dois, a polícia é violenta, corrupta e seletiva e adota procedimentos que colocam vidas em risco. Esses procedimentos desestabilizam o cotidiano local, provocando o descontentamento das pessoas que residem nessas áreas. Destaco algumas falas:

O fato de ser comunidade de baixa renda, ou melhor, favela. Entram de forma violenta, sempre entraram com violência, sempre (Machado da Silva \& Leite, 2008:58).

[...] Eles [os policiais] sabem que a maioria das pessoas [...] é leiga. Não tem de fato um esclarecimento de quais são os direitos dela, de quais os direitos da PM, da civil... Então eles já se prevalecem disso (Machado da Silva \& Leite, 2008:59). 
Ainda segundo os pesquisadores, a forma como os policiais conduziam operações dentro de favelas, subindo o morro de qualquer forma, muitas vezes dando início a trocas de tiros com traficantes sem assumir cuidados para preservar a integridade física dos que lá vivem, era uma das principais queixas dos moradores. Mas o problema não se restringia a colocar vidas em risco; agressões ou práticas que geravam constrangimentos, vivenciadas como humilhação, também foram problematizadas.

[Os policiais] pegaram um cara atrás da minha casa e simplesmente invadiram a minha casa. Minha casa foi arrombada [...] porque pegaram alguém lá atrás [...]. Devem ter pensado que todas as casas ali eram suspeitas, ali na área. Eles não respeitam, não! (Machado da Silva \& Leite, 2008:58, grifo meu).

Mais uma vez, é importante indagar se estamos diante de uma associação entre práticas policiais e desrespeito, pura e simplesmente. Quando o morador questiona se o fato de ter um membro da quadrilha próximo a sua residência faz dele também um suspeito e autoriza que os agentes invadam sua casa, desconsiderando seus direitos, há algo mais na sua queixa do que a insatisfação com a "violência policial" propriamente dita. O que é desrespeito nesse caso? O procedimento policial em si ou o fato de esse procedimento revelar que, para os agentes, todos ali são marginais em potencial? Os policiais não respeitam o direito dos moradores de não terem suas casas invadidas de forma arbitrária ou não respeitam o morador que não é "bandido", tratando todos da mesma maneira? Vejamos outras falas:

Atira pra qualquer lado, não quer saber [...]. Eles entram da ponta do beco, atirando [...]. Porque a polícia não quer saber em quem ela vai atirar, se ela vai atingir o bandido, se ela vai atingir o trabalhador. Não quer saber, está atirando (Machado da Silva \& Leite, 2008: 65, grifo meu).

O policial não conhece ninguém, não quer saber em que casa ele vai entrar. (Machado da Silva \& Leite, 2008:64).

\section{O caso de Pavão-Pavãozinho e Cantagalo}

O interesse analítico nos significados que a expressão "respeito" adquire foi estimulado a partir da minha pesquisa sobre o sentido que os habitantes das favelas do Cantagalo e Pavão-Pavãozinho atribuíam à atuação policial na região onde moravam (Cardoso, 2013). As duas favelas situam-se entre os bairros de Copacabana e Ipanema, Zona Sul do município do Rio de Janeiro, ${ }^{5}$ e pelos idos de 2000 foram palco da implantação do Grupamento de Policiamento em Áreas Anuário Antropológico/2013, Brasília, UnB, 2014, v. 39, n. 2: 261-282 
Especiais (GPAE), iniciativa da Secretaria Estadual de Segurança Pública inspirada no modelo de policiamento comunitário. Entre 2001 e 2007, acompanhei a atuação do GPAE nas duas favelas em busca da percepção dos seus moradores sobre o projeto. Em 2013 e 2014, retornei ao campo, agora interessado em comparar as significações locais sobre a Unidade de Polícia Pacificadora (UPP), instalada nas localidades em 2009, com aquelas elaboradas pelos meus interlocutores sobre o GPAE. O objetivo era problematizar o papel das reclamações, das demandas, das concepções de direitos e justiça construídas localmente para o sucesso ou fracasso de projetos inspirados na filosofia do policiamento comunitário e/ou de proximidade. ${ }^{6}$

Há diversas similaridades entre as narrativas coletadas por Machado da Silva \& Leite (2008) e as ouvidas por mim durante incursões em campo. Por exemplo, relatos sobre a brutalidade de traficantes e policiais, insultos e humilhações públicas, insinuações que indicam a existência de acordo corrupto entre os dois grupos, referências a um passado em que líderes dos grupos criminosos cuidavam do bem-estar da localidade e queixas dos tiroteios correspondem a parte significativa do que os meus interlocutores tinham a dizer sobre as experiências cotidianas com a polícia e com o tráfico.

Em campo também pude notar certas precauções assumidas por moradores não envolvidos com o crime organizado para evitar problemas e minimizar riscos. Por exemplo, o cuidado de não fixar o olhar por demasiado tempo nos homens ou adolescentes que pertencem ao tráfico quando se transita dentro da favela ou na sua via de acesso. Outro cuidado era o de conversar com o pesquisador sobre assuntos considerados delicados somente dentro de suas casas e após a confirmação de que não havia ninguém próximo à residência que pudesse representar uma ameaça. Essa era uma habilidade desenvolvida a partir do saber local, que busca "ler os sinais" de iminência de um confronto armado ou qualquer outra situação que coloque a própria vida em risco. Todos esses são comportamentos que Machado da Silva (2008) atribui ao impacto da "sociabilidade violenta" nas favelas fluminenses.

Todavia, minha experiência fez-me questionar até que ponto podemos considerar que a presença e atuação de policiais e traficantes representa uma desestabilização no cotidiano das favelas, tal como pressupõe Machado da Silva (2008). Recorro às anotações que fiz em meu caderno de campo, em maio de 2014, quando, mais uma vez, estive no Pavão-Pavãozinho. ${ }^{7}$ No começo da tarde de uma segunda-feira, enquanto me encaminhava para subir a favela, notei que na Avenida Nossa Senhora de Copacabana, na altura do acesso ao meu destino, havia dois policiais militares fitando o ponto de acesso da Rua Saint Roman. 
Poucos metros adiante, no cruzamento entre a Saint Roman e a Sá Ferreira, na altura onde se delimita a fronteira, por assim dizer, entre a favela e o bairro de Copacabana, encontravam-se mais quatro policiais militares, dois portando fuzis e os outros dois portando escopetas, todas armas de grosso calibre. A cerca de trezentos metros desse ponto, onde fica a base do bondinho que conduz os moradores aos pontos mais altos da favela, estavam mais dois policiais, também fortemente armados.

Todos esses agentes pareciam fazer parte do cenário cotidiano. Os policiais conversavam entre si aparentemente de maneira descontraída. A Rua Saint Roman estava bastante movimentada naquele horário. Os transeuntes se exprimiam entre os carros, os caminhões e os numerosos ambulantes que comercializavam frutas, ocupando a calçada e parte da rua. Os bares no caminho estavam com seu habitual público, que se encontrava sentado em torno de mesas, bebendo cerveja e jogando conversa fora. Havia jovens descendo em direção à praia, pessoas retornando de Copacabana, garis recolhendo o lixo deixado na rua. Nada no comportamento daquelas pessoas poderia fazer-me concluir que a presença de policiais, portando armamento pesado de forma ostensiva, desestabilizava a rotina local.

O cenário descrito acima, assim como os cuidados assumidos pelos moradores na tentativa de evitar se indispor com o "movimento", permitem questionar em que medida as implicações da presença de grupos armados dentro das favelas representam, de fato, uma desestabilização da rotina. Conforme os dados etnográficos, na verdade, estamos diante de acontecimentos que, na perspectiva dos residentes em favelas, estão devidamente assimilados à rotina local. Isso me permite recolocar a pergunta que perpassa por este artigo: o que, então, incomoda esses moradores?

Outra similaridade entre o material de pesquisa de Machado da Silva \& Leite (2008) e o meu é a recorrência com que as oposições respeito/desrespeito e pessoa de bem/bandido surgiam nas narrativas dos meus interlocutores. De tanto escutá-las durante a pesquisa de campo, passei a questionar sua importância e, com o tempo, dei-me conta de que não estava diante de simples palavras decorrentes de associações livres. Tratava-se de categorias centrais que estruturavam as narrativas sobre suas experiências cotidianas e revelavam concepções de mundo sobre direitos e justiça.

Como já expus em outro artigo (Cardoso, 2013), a percepção que meus interlocutores tinham da prática policial nas favelas era construída a partir do entendimento de que os agentes não os respeitavam. Para eles, o desrespeito se materializava não apenas pelo uso excessivo e ilegal da força contra as pessoas 
que não pertenciam ao movimento, como pelas práticas interpretadas como descaso com suas vidas e segurança (incursões e tiroteios), ou omissões que permitiam ao "movimento" ditar as regras de sociabilidade e circulação dentro das favelas (como interpretavam a corrupção policial). A experiência do desrespeito estava ligada à visão de que determinada pessoa na favela, "trabalhadora" ou "de bem”, reconhecidamente não associada a comportamentos socialmente reprováveis, segundo os parâmetros locais, sofrera uma injustiça e tivera sua dignidade desconsiderada ou afrontada. Isso me permitiu concluir que meus interlocutores estavam demonstrando sua indignação com o não reconhecimento da condição moral diferenciada das "pessoas de bem" dentro das favelas, fosse pela polícia, fosse pelo tráfico. Nesse sentido, tratamento respeitoso era entendido como um direito das pessoas que não aderiram ao tráfico, como é possível perceber das falas que se seguem:

Eu e minhas filhas trabalhamos duro. Nós pagamos tudo direitinho, luz, [TV] cabo. A diferença agora com o pessoal da rua é que a gente mora no alto e a polícia não respeita a nossa casa nem nossa vida. Nós pagamos igual a qualquer um, mas ainda somos tratados como bicho. Como bicho não, como gente da pior espécie, porque bicho todo mundo trata bem (Cardoso, 2013:179).

[...] Pra polícia só tem bandido aqui. Na verdade, eles sabem que não é assim, que tem muita gente trabalhadora que não faz nada errado, que não se mete com o crime. Mas eles não se importam, fingem que é tudo bandido. Não tem um que morra que não aparece no jornal dizendo que era envolvido. Então é todo mundo (Cardoso, 2013:180).

Mais recentemente, um acontecimento narrado por uma das minhas interlocutoras, que chamarei aqui de R., indica a permanência da mesma estrutura narrativa ancorada na chave interpretativa local de respeito/desrespeito, encontrada por mim entre 2001 e 2007. ${ }^{8}$ Ela contou-me que um membro do bando local ameaçou uma das suas filhas, dizendo-lhe que poderia alvejá-la com uma arma de fogo.

Aqui onde ela mora é a boca de fumo, né. Um dia a C. ia passando (em direção a sua casa) e um deles (traficante) disse: "entra logo senão tu vai levar uma bala na tua cara, a'”. Depois eu disse pra ela (filha) assim: "porque você não perguntou se estava falando contigo?”. Ou então porque não me ligou, que eu tinha ido lá perguntar: "ô seu moleque safado, porque está falando assim? Não tem respeito não? Eu vou procurar um outro maior que tu, que é o dono, é 
o diabo, não sei, pra poder falar que você está desrespeitando morador. Aqui morador nenhum desrespeita vocês (entrevista concedida em maio de 2014).

Meses antes dessa entrevista, eu havia conversado com H., segunda filha de R., sobre suas impressões da polícia e do trafico, e ela havia recorrido às categorias "pessoa de bem", "trabalhador" e "bandido" para discorrer sobre o assunto. Então pedi que ela definisse "pessoa de bem”. A resposta foi a seguinte:

Pra mim, é a pessoa que não tem envolvimento com o trafico, diretamente com o tráfico [...]. Tem a ver com o trabalhar, com o não se envolver, não está diretamente ligado, acho que é isso, "pessoa de bem”, dentro da favela que eu tô falando, não quer dizer que seja o bonzinho, não. Não acredito também no bonzinho nem no coitadinho (entrevista concedida em outubro de 2013).

No desenvolver dessa conversa, H. também afirmara que a violência policial contra os envolvidos com o tráfico não era um grande problema: "porque merece, talvez, acho que é isso", me disse. O que a incomodava era quando as pessoas "trabalhadoras" ou "de bem" eram atingidas pela ação policial.

\section{"Trabalhadores", "pessoas de bem" e "desrespeito"}

O que é entendido por essas pessoas como "desrespeito"? A resposta à pergunta começa a ser desenhada a partir da identificação de dois pontos recorrentes nas narrativas sobre a polícia e sobre o tráfico. Um é a construção de uma identidade contrastiva, carregada de conteúdo moral, que diferencia quem aderiu ao "movimento" e quem não aderiu. O outro é o entendimento de que os policias confundem ou desconsideram essa diferença, tratando todos nas favelas da mesma forma.

Construções discursivas que opõem "gente de bem”, "pessoa de bem”, “trabalhador" e "pai ou mãe de família" ao "movimento", aos "bandidos" ou aos "marginais" são comuns nas narrativas de moradores de favelas. Como a lista de autores que identificaram sua vigência é demasiado grande, lembrarei apenas que, desde o trabalho de Alba Zaluar na Cidade de Deus (1985), ficou claro que essas categorias desempenham papel importante na construção da identidade dos moradores de áreas dominadas por grupos criminosos. .9 Àquela altura, Zaluar já havia identificado a carga moral presente na oposição trabalhador/ bandido, tal como elaborada pelos moradores da localidade acompanhada em sua pesquisa. Da perspectiva de quem não aderiu ao tráfico, dizer-se trabalhador, enfatizando seu compromisso com o sustento da família por meio de atividades mais ou menos lícitas que não envolvam assalto a mão armada ou venda de drogas, era reafirmar-se moralmente superior àqueles que buscaram ganhar Anuário Antropológico/2013, Brasília, UnB, 2014, v. 39, n. 2: 261-282 
dinheiro de maneira fácil, e por isso entraram para o tráfico (Zaluar, 1985:88). Isso permitiu a Zaluar concluir que, para o indivíduo que não pertencia ao grupo criminoso, ao menos discursivamente, era a adesão a uma determinada ética do trabalho que diferenciava moralmente uns dos outros. ${ }^{10} \mathrm{O}$ mesmo pode ser observado no material publicado por Machado da Silva \& Leite e nos depoimentos recolhidos por mim ao longo dos últimos treze anos. As pessoas ouvidas por esses dois pesquisadores, ao falarem das suas experiências cotidianas e das suas impressões sobre a polícia e o tráfico, faziam-no sublinhando a sua condição de "trabalhadoras" ou "gente de bem", colocando-se como moralmente superiores aos indivíduos que pertenciam à organização criminosa.

Todavia, essa constatação é antes o ponto de partida do que uma linha de chegada dentro do que proponho neste artigo. Podemos identificar que é sobre o prisma da inaptidão ou do desinteresse em distinguir "trabalhadores" ou "gente de bem" dos "bandidos" ou "marginais" que o comportamento adotado por policiais nas favelas é interpretado por seus moradores. O que gera indignação não é propriamente a truculência policial ou a desorganização da rotina que sua presença ou atuação nas favelas desencadeia, mas a incapacidade que seus agentes têm de discernir uns dos outros, tratando todos da mesma maneira. Em outras palavras, e respondendo à pergunta lançada em um dos parágrafos acima, desrespeito é tratar a "gente de bem" como se marginais fossem.

Os policiais não respeitam os moradores [...]. Já chegam atirando, confundem os trabalhadores com os marginais (Machado da Silva \& Leite, 2008:65, grifo meu).

Conceber-se como moralmente superior fundamenta a expectativa de receber tratamento respeitoso dos policiais e dos traficantes. Comportamentos que não expressem o reconhecimento da diferença entre "trabalhadores" e "bandidos" são significados como uma afronta à dignidade da "gente de bem", experiência que se aproxima daquilo que Cardoso de Oliveira (2002) denominou de insulto moral. Para o que interessa neste artigo, ou seja, a observação da dimensão simbólica dos depoimentos, o que de fato organiza as narrativas colhidas por Machado da Silva \& Leite é o descontentamento com o não reconhecimento da condição moral das pessoas que, em razão de suas escolhas (aderir ou não ao tráfico), deveriam ter sua dignidade preservada. Abusos de autoridade, agressões, execuções e corrupção, práticas geralmente atribuídas a policiais e traficantes, incomodam a "gente de bem". Na mesma medida, também me parece incontroverso que o comportamento assumido ao longo dos últimos anos por indivíduos que pertencem ao crime organizado ou à polícia reconfigurou padrões de interação social tradicionalmente estabelecidos e modificou a maneira como os 
espaços públicos dentro das favelas eram utilizados (e significados), em prejuízo da maioria dos residentes dessas áreas. Trata-se de um fenômeno que Machado da Silva \& Leite apontam como um desdobramento da "sociabilidade violenta".

Entretanto, encerrar a problematização nesse ponto é insuficiente. As falas dos moradores de favelas tratadas aqui revelam a complexidade com que eles elaboram suas experiências e significam a presença e o comportamento dos indivíduos que eles próprios identificam como seus algozes. Há nuances que apenas são passiveis de apreensão quando contextualizamos as falas e as categorias recorrentemente utilizadas. Como já lembrou Strathern, para se evadir de análises baseadas em conceitos exógenos aos elaborados pelos grupos estudados, que guardam pouca ou nenhuma relação com o universo observado, não é suficiente substituí-los pela exposição dos conceitos ou das narrativas nativas. É importante dedicar atenção especial às categorias utilizadas pelo grupo estudado para narrar suas experiências e convicções, assim como aos contextos particulares em que essas categorias são produzidas (Strathern, 2006:33). Esse procedimento, diga-se de passagem, não representa em si algo novo na disciplina, visto que, ao menos desde Malinowski (1978), o fazer antropológico consiste em compreender comportamentos e conceitos nativos a partir dos significados atribuídos pelos atores sociais observados. Em outras palavras, é preciso contextualizá-los.

No caso dos moradores de favelas acompanhados por Machado da Silva \& Leite, não há como compreender suas reclamações sem se ater às expressões "desrespeito" e "respeito", buscando elucidar seus significados e as situações onde cada uma delas emerge. Em várias passagens, determinados comportamentos adotados por policiais ou traficantes são classificados como práticas desrespeitosas, o que gera insatisfação, desencadeia reclamações e precipita reivindicações sobre o comportamento que se espera dos agentes desses dois grupos. Poderíamos então dizer que, no entendimento dessas pessoas, o comportamento dos traficantes e dos policiais é, em si mesmo, um ato de desrespeito? Como apontei anteriormente, a resposta a essa pergunta é não.

No cerne das queixas não estão as práticas classificadas de violentas e seus impactos na rotina das favelas, mas o seu uso indiscriminado e suas consequências para determinado "tipo de pessoa" que reside nessas áreas — aspecto que não passou despercebido por Machado da Silva \& Leite, como demonstrarei adiante. Retomando meu argumento, observa-se que parte significativa das críticas sobre os comportamentos elencados como problemáticos articulam-se com a percepção de que os policiais não são capazes ou não se interessam em discernir "gente de bem" de "bandidos", e de que os traficantes, ao longo das últimas décadas, modificaram para pior a forma como se relacionavam com os demais moradores Anuário Antropológico/2013, Brasília, UnB, 2014, v. 39, n. 2: 261-282 
de favelas, assim como a maneira como ocupavam os espaços públicos dentro dessas localidades. Isso me permite sustentar que é apenas quando policiais e traficantes agem de forma a ignorar a diferença entre uns e outros, vitimando a "gente de bem", que se configura uma situação de desrespeito.

Ora, se o problema está no desrespeito que determinados comportamentos de policiais e traficantes provocam, e se o entendimento sobre a ocorrência do desrespeito depende da identificação do tipo de pessoa vitimada, pode-se considerar que a questão central tematizada pelos moradores é antes a desconsideração da "gente de bem" do que a materialidade dos atos cometidos por traficantes e/ou policiais. No que concerne à perspectiva dos moradores não envolvidos com o tráfico, é a percepção de desconsideração que informa o comportamento policial e criminoso como problemático e ofensivo.

A experiência do desrespeito articula as reivindicações por reconhecimento (Honneth, 2003; Taylor, 1994) e tratamento respeitoso, entendido, no caso dos moradores de favelas, como um direito de determinadas pessoas, detentoras de qualidades morais particulares (Cardoso, 2013). O conteúdo do material apresentado por Machado da Silva \& Leite aponta para a mesma direção. As narrativas das pessoas ouvidas pelos dois pesquisadores se assentam na percepção de que o comportamento dos policiais revela desinteresse ou incapacidade de reconhecer a diferença entre "gente de bem" e "marginais". O problema, como disse uma pessoa entrevistada por Machado da Silva \& Leite, é a confusão feita pelos policiais. Já no caso do comportamento dos traficantes, o problema está no fato de que o reconhecimento da diferença entre eles deixou de ter um conteúdo moral que favorecia os "trabalhadores" — entendimento que no passado, segundo esses moradores, garantia um tratamento respeitoso para com eles. Isso indica que o ponto nevrálgico das reclamações é a desconsideração significada como um insulto, um atentado à dignidade de quem deveria ser alvo de tratamento que reconhecesse sua condição moral.

\section{O que eles dizem quando falam: respeito em segundo plano}

Na parte final de seu artigo, Machado da Silva \& Leite tecem comentários sobre determinados aspectos cosmológicos das narrativas que, a meu ver, são fundamentais para dimensionar o conteúdo das queixas dos favelados. É o caso, principalmente, da observação de que as críticas dirigidas aos policiais não se deviam à utilização de métodos violentos, mas ao "caráter indiscriminado da ação que não distingue entre 'gente de bem' e 'marginais' [...]. O que os moradores criticam é menos a violência policial em si e mais a falta de seletividade de seu objeto" (2008:73). 
Mais adiante, complementando o raciocínio, eles apontam que, para as pessoas pesquisadas, o problema seria o "desrespeito às diferenças e hierarquias internas que constituem a versão local de ordem social” (2008:74). A postura desrespeitosa desconsideraria a "alteridade dos favelados por parte dos agentes da sociabilidade violenta" (2008:74). Essas passagens não deixam dúvidas de que a constante utilização das expressões "respeito", "trabalhadores", "gente de bem" e "marginais" nos depoimentos não passou despercebida por Machado da Silva \& Leite, assim como não passou despercebido como elas eram utilizadas para expressar insatisfações, marcar diferenciações, estabelecer hierarquias e justificar demandas por tratamento que os moradores consideravam reconhecedor da sua condição moral.

Contudo, do meu ponto de vista, a preocupação com o mapeamento dos eventos relacionados à desestabilização das rotinas fez com que ficasse em segundo plano a problematização da dimensão simbólica das narrativas para produzir uma interpretação daquilo que Machado da Silva \& Leite consideram ser seu sentido subjacente. Justamente por isso, questões como desconsideração da alteridade e demandas, apesar de abordadas pelos dois, não são centrais para a conclusão. Para Machado da Silva \& Leite, a instabilidade das rotinas, desencadeadora de medo e ansiedades, é a questão que perpassa por todas as queixas, mobilizando-as e articulando-as. Isso fica claro nas passagens a seguir:

A conclusão geral sobre as críticas à violência policial pode ser resumida da seguinte maneira: elas denunciavam a violência, mas referem-se a outro problema: a quebra da rotina (Machado da Silva \& Leite, 2008:73).

A conclusão geral sobre as críticas dirigidas à violência criminal caminha na mesma direção das críticas à atuação dos policiais. Não é propriamente nem o crime nem a violência que organizam o discurso crítico, mas sim, como se viu nos relatos analisados, a interferência desta forma de vida sobre o fluxo da rotina da vida nos territórios das favelas (Machado da Silva \& Leite, 2008:75).

A construção de uma interpretação sobre o conteúdo das narrativas que não se debruçasse sobre os significados atribuídos pelos participantes das pesquisas às suas experiências não correspondia ao desafio que Machado da Silva \& Leite se colocaram no início do artigo. Explico: ao assumirem como objetivo a compreensão de como os residentes de favelas significavam o cotidiano das localidades onde viviam, ambos defendem o uso de um modelo analítico que permaneça "no limite da experiência vivida, enfatizando a contingência, variedade e a inconstância dos laços entre as diferentes situações e nas práticas dos autores” 
(2008:52). Essa abordagem permitiria ao pesquisador "reconhecer e priorizar analiticamente o modo específico de constituição das diferentes formações sociais" (Machado da Silva \& Leite, 2008:53). Assim, argumentam eles, pode-se observar a partir de casos específicos e de relações concretas como a cidadania é significada pelos agentes estatais responsáveis pela aplicação da lei e manutenção da ordem pública e por representantes de diferentes grupos sociais.

Para justificar a escolha, os autores recorrem à noção de "cidadania de geometria variável” (Lautier, 1987:87 apud Machado da Silva \& Leite, 2008:54). Segundo Lautier, os direitos de cidadania no Brasil estariam sujeitos a múltiplas significações definidas situacionalmente sob influência de valores hierárquicos presentes na sociedade brasileira. Ainda nessa linha de pensamento, segundo Machado da Silva \& Leite, Lautier “[...] admite que nem sempre a linguagem dos direitos é hegemônica e que, quando isso ocorre, o conceito prático de cidadania surge diferencialmente 'indexado' às situações e aos problemas concretos" (2008:54). A ideia de "cidadania contexto-dependente” é importante para Machado da Silva \& Leite porque sustenta suas escolhas de privilegiar os significados que os moradores atribuem a suas experiências.

Esse é um tipo de entendimento desde muito incorporado na antropologia interessada nos meios institucionais e não institucionais de administração de conflitos. O fato de que as leis que visam regular o comportamento de sociedades ou grupos constituem e expressam, em alguma medida, suas próprias concepções de mundo já foi exaustivamente demonstrado por antropólogos como Geertz (2002) e Gluckman (2006). Isso certamente não é ignorado por Machado da Silva \& Leite. Aponto isso apenas para abrir caminho para desdobramento derivado dessa constatação. Se as leis são, para usar uma expressão cara a Geertz, um saber local, devemos considerar também que o entendimento sobre elas está sujeito a variações dentro de uma mesma sociedade, de acordo com o grupo social acompanhado (Cardoso de Oliveira, 2011).

Levando essa perspectiva a sério, devemos observar que, não apenas em um universo onde vigorem concepções de mundo que produzem e reproduzem uma imagem hierarquizada de si — responsáveis por alimentar desigualdades sociais e políticas —, há a possibilidade de identificar interpretações dos direitos de cidadania "contexto-dependentes". Não se trata de uma característica peculiar de sociedades marcadas por valores hierárquicos e pela desigualdade social, como sugere Lautier. Em todo e em qualquer lugar, a dimensão formal dos direitos está sujeita a filtros que determinam sua compreensão; ou seja, todas as representações sobre o mundo são contexto-dependentes, por óbvio. 
De todo modo, Machado da Silva \& Leite escutaram as reclamações dos moradores de favelas, identificaram as práticas e os eventos que incomodavam os locais, assim como a recorrência de certas expressões nas suas falas, mas não assumiram a tarefa de problematizar as categorias pelas quais elas construíam e estruturavam suas narrativas. Ficou faltando justamente contextualizar e problematizar o conteúdo das narrativas, explorando sua dimensão contexto-dependente.

\section{Considerações finais: concepções de direitos, igualdade e diferenciações}

Recorro às reflexões de Luís Roberto Cardoso de Oliveira (2008), Daniel Simião (2005) e Lia Zanotta Machado (2010), no concernente à controvérsia sobre a indissociabilidade entre violência e insulto moral, para sustentar que as insatisfações dos moradores de favelas tratados neste artigo derivam da significação atribuída a determinadas práticas ou comportamentos adotados por policiais e/ou traficantes. Machado diverge dos dois antropólogos no que se refere à sugestão feita por eles de que seria incorreto falar de violência quando um ato de uso acintoso da força física não é entendido culturalmente como um gesto de desconsideração, moralmente concebido como um insulto. Segundo Cardoso de Oliveira, seria inadequado falar de violência "quando não houver agressão de ordem moral, dando sentido ao aparente paradoxo de que a 'violência física', sem um componente simbólico/moral, seria apenas uma abstração” (2008:139).

Na prática, esse entendimento permite tanto a Cardoso de Oliveira quanto a Simião questionar a existência de uma relação necessária entre agressões físicas e desconsideração. Machado contra-argumenta destacando que atos caracterizados pelo uso acintoso da força física são carregados de sentido moral que implicam, invariavelmente, a efetivação de "uma forma de comunicação que visa limitar ou restringir a ação do outro, ou seja, que implica, ao mesmo tempo, formas de consideração e/ou desconsideração" (2010:119). Nesse sentido, diz ela, podemos conceber a prática de agressões morais sem agressões físicas, mas "de forma nenhuma se pode dizer que há agressões ou correções físicas intencionais que não se recobrem de sentidos morais relacionais” (2010:119).

A despeito das divergências, os três parecem concordar que as práticas concebidas pelos atores sociais como abusivas ou violentas estão repletas de sentidos morais que as classificam como desconsideração, agressão ou insulto. De modo que não há como dissociar atos considerados violentos ou problemáticos da sua dimensão moral de ofensa. Ao tomar isso como premissa, é necessário levar a sério o alerta feito por Cardoso de Oliveira de que o enfoque na materialidade Anuário Antropológico/2013, Brasília, UnB, 2014, v. 39, n. 2: 261-282 
daquilo subjacente ao rótulo de violência nos faz ignorar que, por vezes, a dimensão moral da violência "constitui o cerne da agressão do ponto de vista da vítima” (2008:135).

A forma como os moradores de favelas verbalizaram seus descontentamentos nos permite indagar se não estamos diante de algo semelhante àquilo que Honneth (2003) e Taylor (1994) denominaram de demandas por reconhecimento, e que Cardoso de Oliveira (2002) tem chamado de expectativa por consideração. Mas o que caracteriza as reivindicações e insatisfações apresentadas até aqui? Machado da Silva \& Leite, após exporem depoimentos dos interlocutores que versavam sobre a suspeição que tinham da polícia, argumentam que essas pessoas não podem confiar em policiais que "neles não reconhecem a dignidade indissociável da cidadania, não consideram nem protegem sua vida e seus direitos e cuja presença no território se faz sempre contra a integridade física dos moradores em geral" (2008:62).

Apenas em parte concordo com essa afirmativa. O material de pesquisa trazido por Machado da Silva \& Leite, de fato, não permite que pairem dúvidas sobre a desconfiança generalizada dos moradores de favelas em relação à polícia, assim como a existência de um inconformismo com o que entendem ser gestos de desconsideração da vida e dos direitos. Nesse ponto, estou de acordo com Machado da Silva \& Leite e posso acrescentar que essa observação pode ser estendida, sem o menor risco de incorrer em imprecisão, para a maioria das pessoas com quem convivi durante minhas incursões nas duas favelas da Zona Sul do Rio de Janeiro. Todavia, discordo dos dois quando associam a desconfiança e as queixas com a inobservância da dignidade inerente à cidadania. Se assim fosse, deveríamos ter constatado que essas pessoas estavam insatisfeitas com o uso seletivo das leis que o comportamento policial materializa, que suas reclamações tinham como horizonte o desejo de aplicação universal e impessoal das leis, e que sua aplicação diferenciada representava uma injustiça.

O material coletado por Machado da Silva \& Leite não nos permite considerar que estamos diante da insurgência de demandas calcadas em princípios igualitários. Não se trata da expectativa de reconhecimento da dignidade inerente à cidadania, o que pressupõe o desejo de tratamento isonômico. As demandas por tratamento respeitoso e as insatisfações com o que consideravam desrespeito não guardavam relação com a inobservância dos preceitos legais que garantem o alcance universal dos direitos de cidadania. Não se trata da insurgência de um movimento que contesta tratamentos diferenciados e que se constrói tendo como horizonte o desejo de consolidação de uma cidadania democrática igualitária. O que as narrativas sugerem é que estamos diante daquilo que Holston 
(2008) chamou de princípios da cidadania diferenciada, em que os direitos são significados como privilégios de determinados grupos.

Tal como aparece nas falas dos interlocutores de Machado da Silva \& Leite, "respeito" não expressa desejo ou demanda por observância à norma escrita no papel, mas sim à pessoa. Essa constatação me permite sugerir que essa categoria local expressa a expectativa do reconhecimento da "substância moral das pessoas dignas" (Cardoso de Oliveira, 2011). Destarte, o que se espera é que o comportamento policial indique esse tipo de reconhecimento. E o que gera insatisfação ou indignação não é a ausência do compartilhamento de uma percepção mútua de igualdade, mas a percepção de que a condição moral não é reconhecida como suficiente para que o sujeito se torne alvo de um tratamento respeitoso, que considere sua dignidade.

Determinados episódios e comportamentos são apontados como problemáticos porque são experimentados pelos moradores de favelas como um insulto moral (Cardoso de Oliveira, 2002, 2013), uma ofensa à dignidade de determinado "tipo de pessoa" que vive nas favelas. Com isso não estou sugerindo, muito menos afirmando, que os tiroteios não são entendidos como um problema entre os habitantes das favelas. Certamente a possibilidade de confronto armado entre traficantes e policiais agregou ao cotidiano dessas áreas um grau de imprevisibilidade que gera insegurança e medo, como Machado da Silva \& Leite muito bem indicaram. No entanto, mesmo episódios dessa natureza são vivenciados como gestos de desconsideração pelos moradores de favelas.

Recebido em: 20 de fevereiro 2014

Aceito em: 24 de abril de 2014

Marcus Cardoso é doutor em Antropologia Social pelo PPGAS/UnB. Pesquisador associado ao Instituto de Estudos Comparados de Administração Institucional de Conflitos (INCT-InEAC) e professor da Unifap. Foi pesquisador colaborador do departamento de antropologia da UnB entre os anos de 2013 e 2014. O presente trabalho foi realizado com apoio do CNPq, Conselho Nacional de Desenvolvimento Científico e Tecnológico - Brasil. Contato: marcusacardoso@gmail.com 


\section{Notas}

1. As narrativas presentes no artigo de Machado da Silva \& Leite foram obtidas por meio de duas pesquisas qualitativas com 15 grupos focais, que contaram com a participação de 150 moradores de 45 favelas do Rio de Janeiro. Além dos grupos focais, foram realizados trabalhos de campo de caráter etnográfico em 3 favelas e 15 entrevistas em profundidade (Machado da Silva \& Leite, 2008:48).

2. Ao contrário do que fazem Machado da Silva \& Leite, e pelos motivos expostos por Strathern, prefiro o termo "socialidade" a "sociabilidade". Segundo a antropóloga britânica, o termo "sociabilidade" carrega uma forte carga valorativa que favorece uma "sentimentalização da noção de relacionalidade" (1999:169), o que faz com que conflitos ou guerras adquiram conotações negativas, em vez de serem tratados como mais uma forma de relação social.

3. Entre 2001 e 2007 e em 2013 e 2014, realizei pesquisa com os moradores das favelas de Cantagalo e Pavão-Pavãozinho, situadas na Zona Sul do município do Rio de Janeiro.

4. "Movimento" é um dos termos usados pelos moradores de favelas e pelos próprios traficantes para se referir ao grupo criminoso que, a partir dessas localidades, controla a venda de drogas ilícitas no Rio de Janeiro.

5.Para saber mais sobre a geografia e história local, consulte Cardoso (2013).

6. Meu retorno ao campo foi financiado pelo CNPq, que, em 2013, concedeu bolsa para a realização de estágio pós-doutoral no Programa de Pós-Graduação em Antropologia Social da Universidade de Brasília (PPGAS/UnB), sob a supervisão do professor Cardoso de Oliveira.

7. Um esclarecimento preliminar é necessário para compreender o relato que se segue. É pela Rua Sá Ferreira e pela Avenida Nossa Senhora de Copacabana, transversais entre si, que se chega à Rua Saint Roman, principal acesso à referida favela.

8. As consoantes utilizadas neste artigo não correspondem às iniciais corretas dos nomes das pessoas que me concederam entrevistas ou com quem conversei.

9. A identidade social de trabalhador ou bandido não pode ser tomada de forma essencializada e estática, a ponto de estabelecer uma separação nítida entre uns e outros que impeça aproximações e rearranjos tanto nas representações sociais quanto nas relações sociais. Zaluar já havia alertado para isso ao dizer que "toda identidade social constrói-se opondo-se a outras num caleidoscópio de identificações que ficam longe da ideia de identidade como algo igual a si mesmo, uno, completo e definitivo" (1985:87). Assim, a “identidade de trabalhador constrói-se em parte por oposição a bandidos e vagabundos que não trabalham. Mas se o trabalho é critério fundamental de diferenciação entre tais categorias, isso não quer dizer que a oposição entre eles seja rígida e absoluta ou que exista, no plano 
das relações sociais, uma segregação claramente demarcada, separando-os completamente" (Zaluar, 1985:132).

10. Contudo, como lembra Zaluar, trata-se menos de uma valorização do trabalho em si do que do compromisso de homens e mulheres em idade adulta com o provento de todos os membros da unidade familiar. "O trabalhador respeitável é membro de uma família para cuja sobrevivência concorre aumentando a renda familiar. O respeito que tem por si próprio e pelos outros, como veremos adiante, advém daí. É esta obrigação com os demais membros da família, em especial quando ele é o provedor principal, que o faz aceitar como positivo o trabalho" (Zaluar, 1985:89).

\section{Referências bibliográficas}

ALVITO, Marco. 2001. As cores de Acari: uma favela carioca. Rio de Janeiro: Editora FGV.

CARDOSO, Marcus. 2010. Como morre um projeto de policiamento comunitário: o caso do Cantagalo e do Pavão-Pavãozinho. Tese de Doutorado, Universidade de Brasília.

. 2013. "A dimensão simbólica dos conflitos: moradores de favela e polícia”. Anuário Antropológico, 1:167-190.

2014. "Demandas por direitos e a polícia na encruzilhada". Revista Brasileira de Segurança Pública, 8(1):154-169.

CARDOSO DE OLIVEIRA, L. R. 2002. Direito legal e insulto moral: dilemas de cidadania no Brasil, Quebec e EUA. Rio de Janeiro: Relume-Dumará.

2008. "Existe violência sem agressão moral?”. Revista Brasileira de Ciências Sociais, 23:135-146.

. 2011. "A dimensão simbólica dos direitos e a análise dos conflitos". Revista de Antropologia - USP, 53:451-473.

2013. "Equality, Dignity and Fairness: Brazilian Citizenship in Comparative Perspective”. Critique of Anthropology, 33(2):131-145.

GEERTZ, Clifford. 2002. "O saber local: fatos e leis em uma perspectiva comparativa”. In: . O saber local. Petrópolis: Vozes. pp. 249-356.

GLUCKMAN, Max. 2006. Politics, Law and Ritual in Tribal Society. Oxford: Transaction.

HOLSTON, James. 2008. Insurgent Citizenship: Disjunctions of Democracy and Modernity in Brazil. Princeton: Princeton University Press. 
HONNETH, Axel. 2003. Luta por reconhecimento: a gramática moral dos conflitos sociais. São Paulo: Ed. 34.

MACHADO, Lia Z. 2010. “Antropologia e feminismo diante da violência”. In:

(org.). Feminismo em movimento. São Paulo: Ed. Francis. pp. 87-134.

MACHADO DA SILVA, L. A. 2008. Vida sob cerco: violência e rotinas nas favelas do Rio de Janeiro. Rio de Janeiro: Nova Fronteira.

MACHADO DA SILVA, L.A. \& LEITE, M. 2008. "Violência, crime e polícia: o que os favelados dizem quando falam desses temas?” In: L. A. MACHADO DA SILVA. Vida sob cerco: violência e rotinas nas favelas do Rio de Janeiro. Rio de Janeiro: Nova Fronteira. pp. 47-76.

MALINOWSKI, B.1978. Os argonautas do Pacífico Ocidental. São Paulo: Abril.

SIMIÃO, Daniel. 2005. As donas da palavra: gênero, justiça e a invenção da violência doméstica em Timor-Leste. Tese de Doutorado, Universidade de Brasília.

STRATHERN, Marilyn. 1999. "No limite de uma certa linguagem”. Mana, 5(2):157-175. 2006. O gênero da dádiva: problemas com as mulheres e problemas com a sociedade na Melanésia. Campinas: Editora da Unicamp.

TAYLOR, Charles. 1994. "The Politics of Recognition”. In: A. Gutmann (Org.). Multiculturalism and the Politics of Recognition. New Jersey: Princeton University Press.

WOORTMANN, Ellen. 1994. Árvore da memória. Anuário Antropológico, 92:113-131.

ZALUAR, Alba. 1985. A máquina e a revolta. São Paulo: Brasiliense. 


\section{Resumo}

Neste artigo, debruço-me sobre dados etnográficos obtidos em diversas favelas cariocas para discutir a dimensão de insulto moral que determinadas práticas conduzidas por traficantes e policiais adquirem para os moradores dessas áreas. Suas narrativas permitem ir além na reflexão sobre como certas categorias recorrentemente empregadas pelos moradores de favelas dão acesso à teia de significados que revelam visões de mundo centrais para compreender o que está em jogo quando essas pessoas falam das suas experiências. Tomar as categorias locais e os contextos nos quais elas surgem como objeto de análise permite-nos vislumbrar determinados episódios e comportamentos que são apontados como problemáticos, pois são experimentados pelos moradores como gestos de desconsideração, uma ofensa à dignidade de determinado "tipo de pessoa" que vive nas favelas.

Palavras-chave: insulto moral, consideração, favelas, violência, polícia.
In this paper I analyze ethnographic data from various Rio's favelas to discuss the moral insult that certain practices conducted by dealers and police mean for the residents of these areas. Their narratives allow us to go beyond the consideration of how certain categories recurrently used by favela residents give access to the web of meanings that reveal worldviews that are central to understanding what is at stake when these people talk about their experiences. Taking local categories and contexts in which they arise as an object of analysis provides insight into certain episodes and behaviors that are seen as problematic as they are experienced by favela residents as gestures of disrespect, an offense to the dignity of a certain 'type of person' who lives in the favelas.

Keywords: moral insult, consideration, favelas, violence, police. 